\title{
A Systematic Review of the Social Network Strategy to Optimize HIV Testing in Key Populations to End the Epidemic in the United States
}

\author{
Kristefer Stojanovski ${ }^{1}\left[\right.$ ] Gary Naja-Riese ${ }^{2} \cdot$ Elizabeth J. King ${ }^{1} \cdot$ Jonathan D. Fuchs ${ }^{2,3}$
}

Accepted: 7 April 2021 / Published online: 19 April 2021

(c) The Author(s), under exclusive licence to Springer Science+Business Media, LLC, part of Springer Nature 2021

\begin{abstract}
The United States (U.S.) has a plan to end the HIV epidemic by 2030. The plan's first pillar prioritizes HIV testing. Social Network Strategy (SNS) is an intervention to reach persons not routinely testing for HIV. We conducted a systematic review of SNS to understand its implementation to optimize HIV testing in the U.S. among key populations. The eligibility criteria included peer-reviewed papers based in the U.S. and focused on HIV testing. We identified and thematically analyzed 14 articles to explore factors associated with successful implementation. Key themes included: (1) social network and recruiter characteristics; (2) strategies for and effectiveness of recruiting key populations; (3) use of and types of incentives; (4) trust, confidentiality, and stigma concerns; and (5) implementation plans and real-world guidance. Cohort studies indicated that SNS detects more incident HIV cases. Partnerships with health departments are critical to confirm new diagnoses, as are developing plans that support recruiters and staff. SNS is a promising strategy to optimize HIV testing among key populations.
\end{abstract}

Keywords HIV testing $\cdot$ Social network strategy $\cdot$ Implementation $\cdot$ Public health practice $\cdot$ End the HIV Epidemic

\section{Introduction}

We are currently in an unprecedented era as policymakers apply the latest advances in HIV treatment and prevention science to end the HIV epidemic in the United States (U.S.). During the 2019 State of the Union Address, the President announced a plan to end the U.S. HIV epidemic by reducing new infections by $75 \%$ in five years and $90 \%$ in 10 years [1]. To achieve these goals, the plan is organized around four key pillars: diagnose, treat, protect, and respond. The first, diagnose, focuses on improving early and timely detection of HIV cases. Treat stresses rapid linkage to HIV care, and initiation of antiretroviral therapy to achieve viral

Kristefer Stojanovski

kristefers@gmail.com

1 Department of Health Behavior and Health Education, School of Public Health, University of Michigan, 1415 Washington Heights, Suite 3800 SPH I, Ann Arbor, MI 48109, USA

2 Center for Learning and Innovation, San Francisco Department of Public Health, 25 Van Ness, Suite 500, San Francisco, CA 94102, USA

3 School of Medicine, University of California, 535 Mission Bay Blvd South, San Francisco, CA 94158, USA suppression, thus eliminating onward transmission [2, 3]. Protect emphasizes protecting those at risk for HIV from becoming infected using novel prevention methods such as pre-exposure prophylaxis [4-7]. Lastly, respond highlights a rapid response to growing HIV infection clusters and prevention of new ones $[8,9]$. Ultimately, the success of the plan hinges on effective strategies to promote HIV testing, the first step in the HIV treatment and prevention cascades [10-12].

Of the estimated 1.2 million adults and youth living with HIV in the U.S., approximately one out of seven individuals do not know their status, and 45\% aged 13-24 years are unaware of their status [13]. The Centers for Disease Control \& Prevention (CDC) currently recommend routine testing during clinical encounters [8] and testing through several non-clinical settings and approaches [9]. These include voluntary counseling and testing sites hosted by trusted community-based organizations as well as venue-based testing, such as at gay Pride events. In addition, public health disease intervention specialists interview those recently diagnosed with HIV to notify sexual partners and encourage them to pursue HIV testing [14-16]. Moreover, self-testing at home has emerged as an important strategy, gaining even greater traction during the COVID-19 pandemic given limits to in-person visits [17-19]. The majority of tests performed 
in non-clinical settings in the U.S. occur in the context of CDC-supported HIV counseling, referral and testing (CRT) services with over 3.2 million tests conducted annually, yielding an overall test positivity of $1 \%$ [10]. The efficiency and acceptability of any non-clinical testing approach are of particular importance to jurisdictions seeking to invest limited resources in methods with higher case detection rates, especially for key populations at higher risk for HIV acquisition, such as men who have sex with men (MSM), who are encouraged to test at least once annually or more frequently [20].

Recent reviews have pointed to the promise of social network strategy (SNS) to efficiently reach key populations for HIV testing [21]. SNS builds on over 40 years of epidemiologic and interventional studies that have leveraged social networks for participant recruitment, including snowball sampling, respondent-driven sampling (RDS), and longchain peer referral [22-24]. SNS is grounded in the idea that members of a social network share the same or similar risks for HIV, tend to trust each other, and may be more willing to adopt behaviors endorsed by members of their network. SNS enlists an initial group of persons at elevated risk or living with HIV as "seeds." These seeds are then tasked with recruiting other persons within their social networks (i.e., network associates) to test for HIV and engage in prevention or treatment services. Seeds receive training and education to help them identify network associates and motivate others to pursue testing, and they often receive incentives to support their recruitment efforts. This method has been shown to effectively detect new HIV positive cases at rates of 5\% or higher [25].

There is a strong theoretical underpinning for how social networks might optimize HIV testing. Social Network Theory studies the relationships and interactions of social groups, communities, and their various networks [26]. Centrality, which identifies how densely connected an individual is to others in their network, is fundamental to the success of the strategy [27] and prioritizes recruiters who are better connected to their social networks. Egocentric networks are tightly connected to one individual, who knows many others, whereas socio-centric networks connect multiple people in a network who, in turn, may be connected to numerous others [28]. Egocentricity is important in the selection of initial seeds, and successful propagation to subsequent waves requires sufficient socio-centricity. In addition, SNS applies the Theory of Planned Behavior, which identifies social norms and pressures as levers in influencing attitudes toward testing, testing intentions, and perceived control of the behavior [29].

While prior studies have documented the efficiency of SNS for HIV case detection, little is known about the facilitators and barriers to SNS implementation or what factors may influence SNS programs' operational success. To speed the translation of evidence to public health practice, we conducted a systematic review of the SNS literature to identify these characteristics and offer recommendations for community-based organizations and public health agencies considering this approach.

\section{Methods}

We conducted a systematic review of the published literature using PubMed and Web of Science databases aligned with the PRISMA criteria [30]. We used a combination of the following terms: "social" and "network" and "strategy"; and "HIV" or "human immunodeficiency virus;" and "United;" and "States". The eligibility criteria for inclusion in the review were as follows: included key populations, such as MSM, person using intravenous drugs, and racial or ethnic minorities; were peer-reviewed, empirical evaluations; were based in the U.S., and focused on SNS specifically applied to HIV testing. We included publications dated from 1981, the start of the social network literature, through June 2020.

Based on these criteria, we identified a total of 979 papers from PubMed and Web of Science to review. We conducted our systematic review of these articles separately for each database. We did not pool databases and remove duplicates at the onset, as we used it as a screening quality metric to assess overlap in our screening between the databases. Therefore, the numbers presented hereafter may include duplicates (from Web of Science and PubMed). Based on the inclusion criteria, we removed a total of 411 studies that were not based in the U.S, 351 papers because they were not focused on HIV testing, and 173 papers because they were not SNS-specific (e.g., they instead focused on respondent-driven or snowball sampling). We excluded an additional eight studies because they were not empirical studies and removed five more because they were not SNS and were missing HIV testing as an outcome. We explicitly included studies that discussed facilitators and barriers of this approach. After combining the two sets of reviews ( $\mathrm{n}=31$ studies), we removed 17 duplicates, leaving a total of 14 unique studies to include in our analysis (Fig. 1). Given that $55 \%$ of the studies were present after reviewing both databases, we believe this supports the quality of our screening and review processes. The papers left for inclusion were published between 2009 and 2018.

\section{Analysis of Papers}

We used thematic analysis to analyze the key factors associated with successful implementation of SNS. We identified themes to understand who SNS reaches for testing and the facilitators and challenges to successful SNS implementation [31]. First, the first author (KS) began to familiarize 


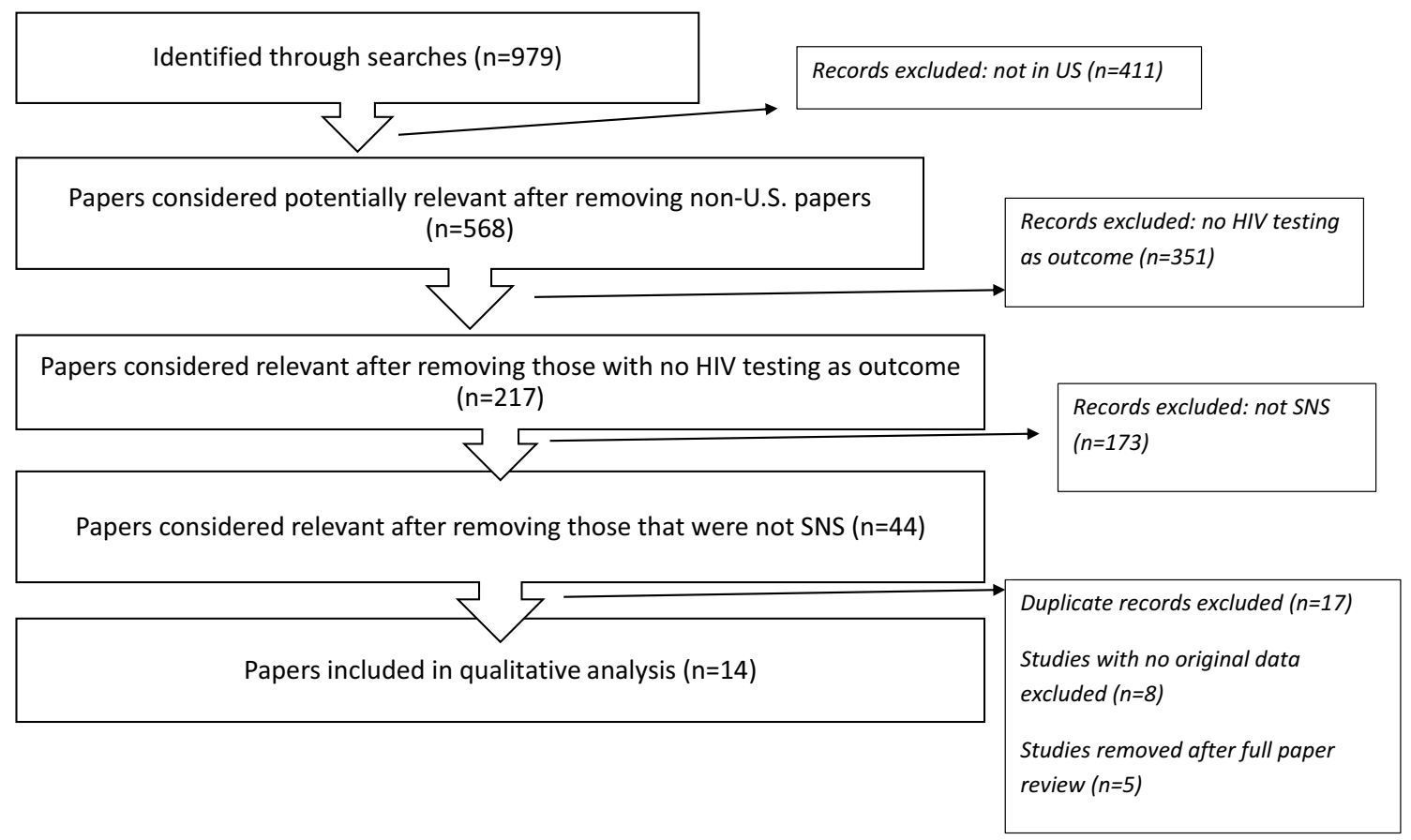

Fig. 1 Diagram of systematic review search and excluded research articles

himself with the findings and main conclusions. Next, KS analyzed the methodological approaches, results, and discussions to understand which priority populations were of primary interest, the studies' locations, and risk of bias. We assessed the risk of bias by exploring potential threats to studies' internal and external validity. For example, we evaluated study designs (e.g., cross-sectional, cohort), presence of comparison groups, and confounding analyses.

KS then extracted the quantitative metrics that typically accompany SNS, including (1) total number of recruiters; (2) the total number of network associates (recruits) recruited; (3) network indices, defined as the number of network associates recruited divided by the total number of recruiters; and (4) new HIV positivity rates (i.e., number of new cases of HIV detected). New cases were determined by reviewing epidemiological surveillance data in some studies, others were cohort studies, and others relied on self-reported knowledge of serostatus. We incorporated this variation in the results. We developed the key themes, both a priori and posteriori. For the a priori themes, we were guided by SNS theory and its critical components, including working with recruiters, incentives, and trust and confidentiality. Posteriori factors were determined by the thematic review itself, including real-world implementation factors, the collaboration required to implement SNS, and the strategy's sustainability. The key themes included: (1) social network and recruiter characteristics; (2) strategies for and effectiveness of recruiting key populations; (3) use of and types of incentives; (4) trust, confidentiality, and stigma concerns; and (5) implementation plans and real-world guidance. KS also identified several subthemes under these main themes to expand upon the findings.

\section{Results}

\section{SNS and HIV Detection Rates}

Half of all the studies were cohort studies [32-38], and the other half were cross-sectional [39-45]. The majority, nine (out of 14) studies, detected an HIV positivity rate over $1 \%$. Of these nine studies, five were cohort studies and four were cross-sectional studies. In the five studies that did not demonstrate HIV rates above $1 \%$, one study was a cohort study in a low-prevalence area ( $0.49 \%$ positivity rate) [33]. In another, SNS was implemented by an infectious disease clinic and emergency department in a cohort study (1\% positivity rate) [35]. Another two were cross-sectional studies in larger geographic areas and focused on Latinx communities (positivity rates of $0.26,0.37 \%$ respectively); these two studies did not achieve their desired sample size [40, 41]. The last was a cross-sectional study that had a $0 \%$ positivity after confirming diagnoses with the health department [42]. Six studies (five cohort, one cross-sectional), out of 14, utilized clinical or health department data to validate the positivity rates [33-35, 37, 38, 42]. Table 1 describes the relevant studies, including the study location, study metrics, and the key populations reached. 


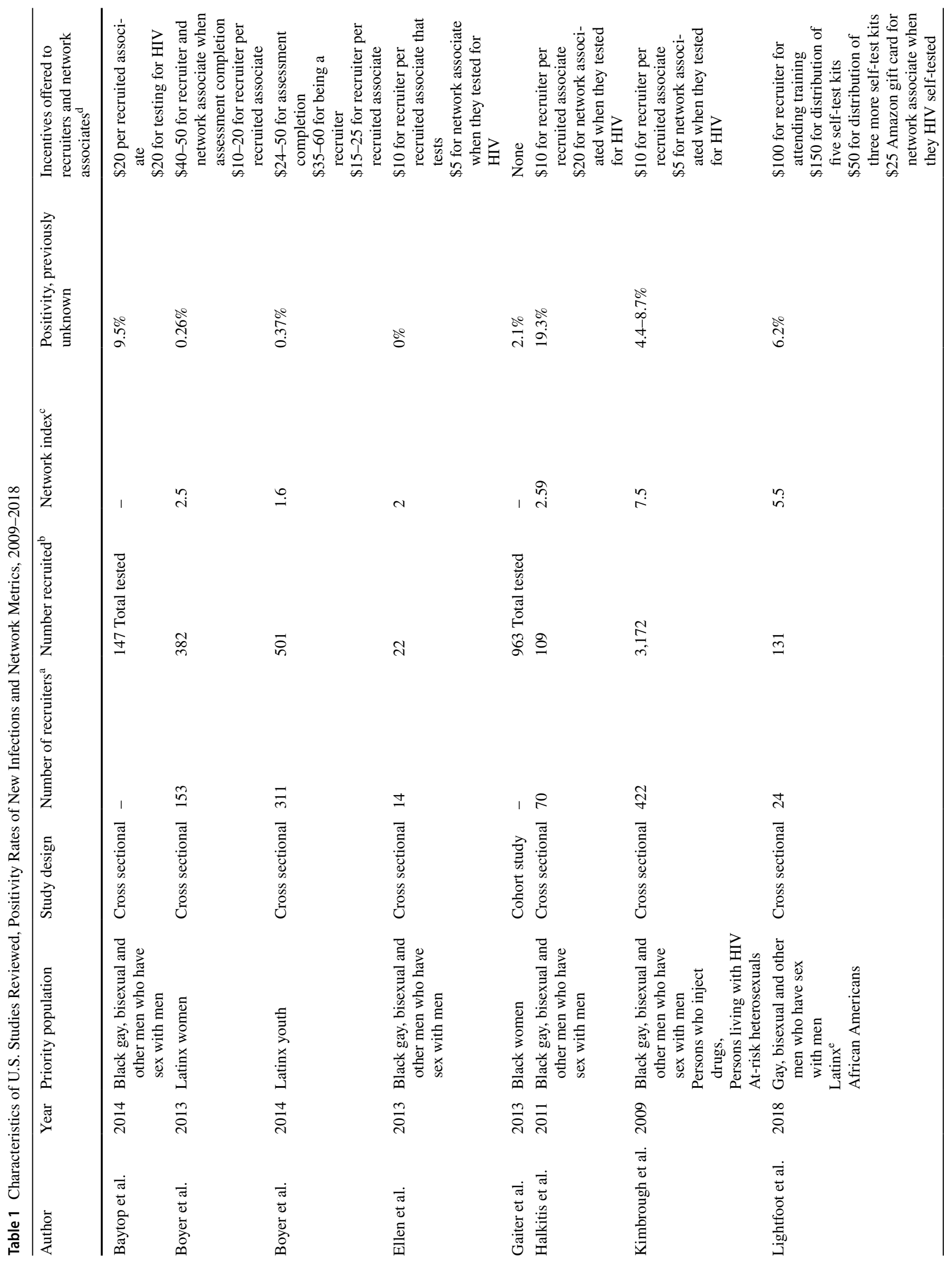




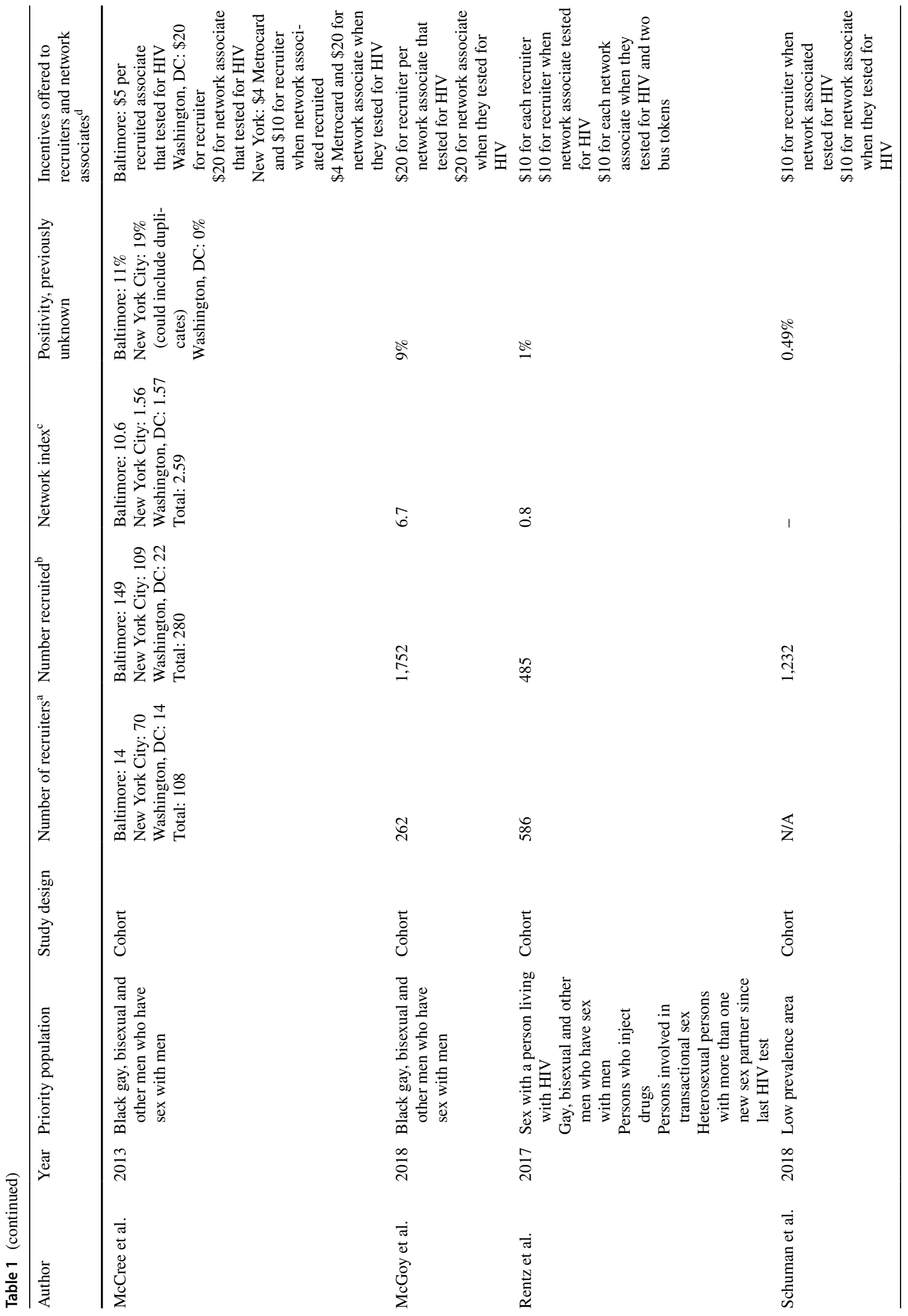




\section{Factors That Influence the Implementation of SNS}

While most published studies document the ability of SNS to uncover undiagnosed HIV cases, various factors promote successful implementation (Table 2).

The thematic analysis of the 14 studies identified five major areas related to SNS implementation: (1) social network and recruiter characteristics; (2) strategies for and effectiveness of recruiting key populations; (3) use of and types of incentives; (4) trust, confidentiality, and stigma concerns, and (5) implementation plans and real-world guidance. These and the respective subthemes are summarized in Table 3.

\section{Social Network and Recruiter Characteristics}

SNS relies on recruiters to engage with their social networks and persuade persons to test for HIV. From a program's inception, implementers must clearly define the priority populations, learn about the connectivity of networks, and appreciate recruiters' centrality in their networks. From the reviewed papers, there was a range of network indices, a standard SNS measurement. The network index is defined as the number of network associates recruited divided by the total number of recruiters. Across all the studies, the network index ranged from 0.8 to 10.6 (Table 1). The wide range of indices reflects the variability in recruiters' centrality within the network and success in recruiting network associates. For example, in one study, $32 \%$ of recruiters accounted for $91 \%$ of linked network associates [44].

SNS assumes people will have similar HIV statuses or associated risks, and sociodemographics. Many of the reviewed papers, 12 out of the 14, indicated that network associates who tested comprised of key populations, including MSM, those having condomless sex, and persons who have not tested before [32-35, 38-44, 46]. Two papers indicated that recruiters' demographics, such as race, ethnicity, and gender, were not associated with the demographics of those recruited $[44,46]$. Three studies did show that PLHIV recruiters were more likely to recruit network associates that tested positive for HIV [40, 44, 46]. To optimize HIV testing efficiency, the review of papers underscores the importance of working with recruiters who intimately know their networks, can foster trusting relationships, and have similar risk factors.

\section{Strategies for and Effectiveness of Recruiting Key Populations}

Many of the studies discussed the facilitators and barriers to effective recruiting. One theme that arose was the need to understand the risk factors of the network. One of the studies described the need to explicitly examine the sexual 


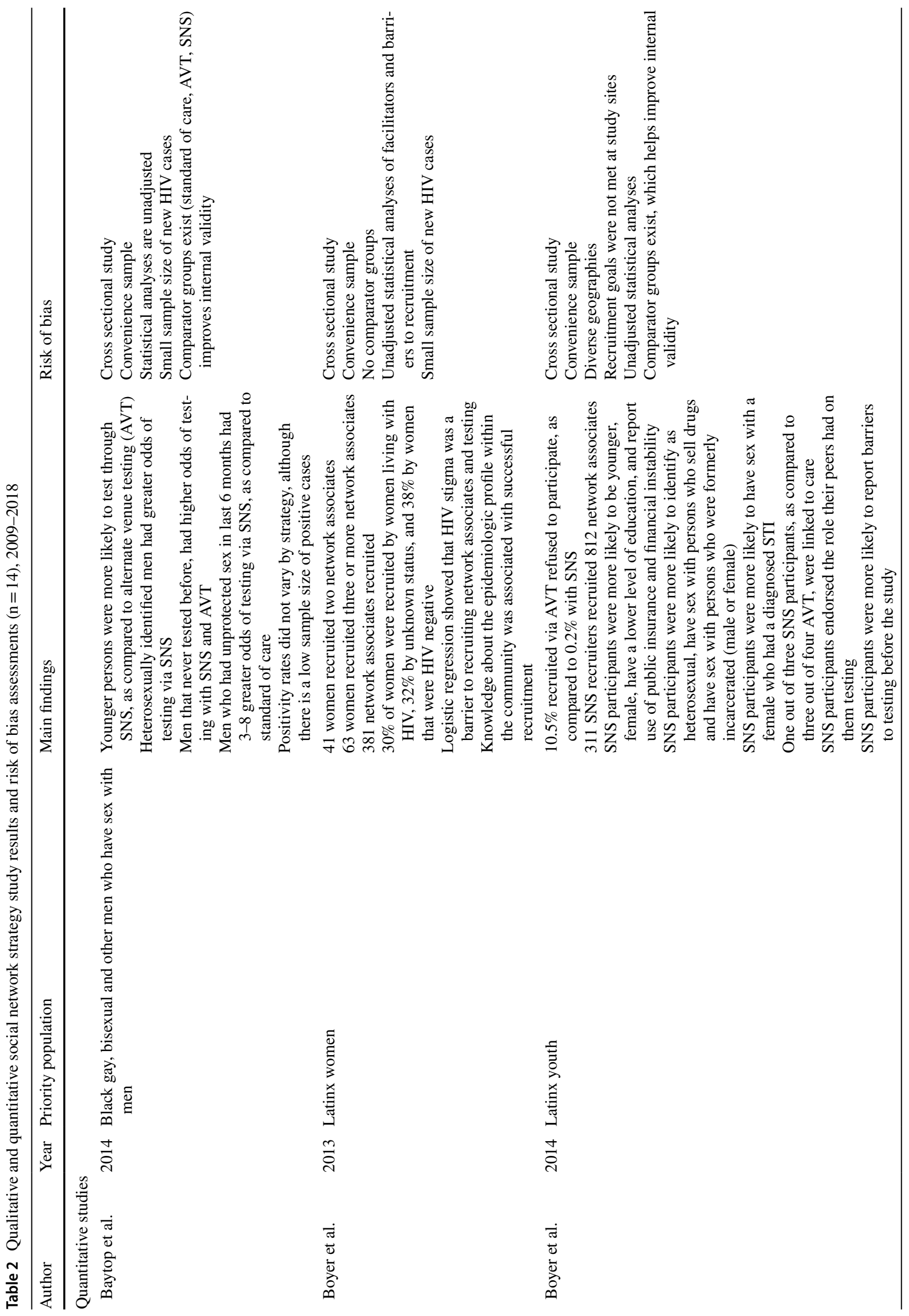




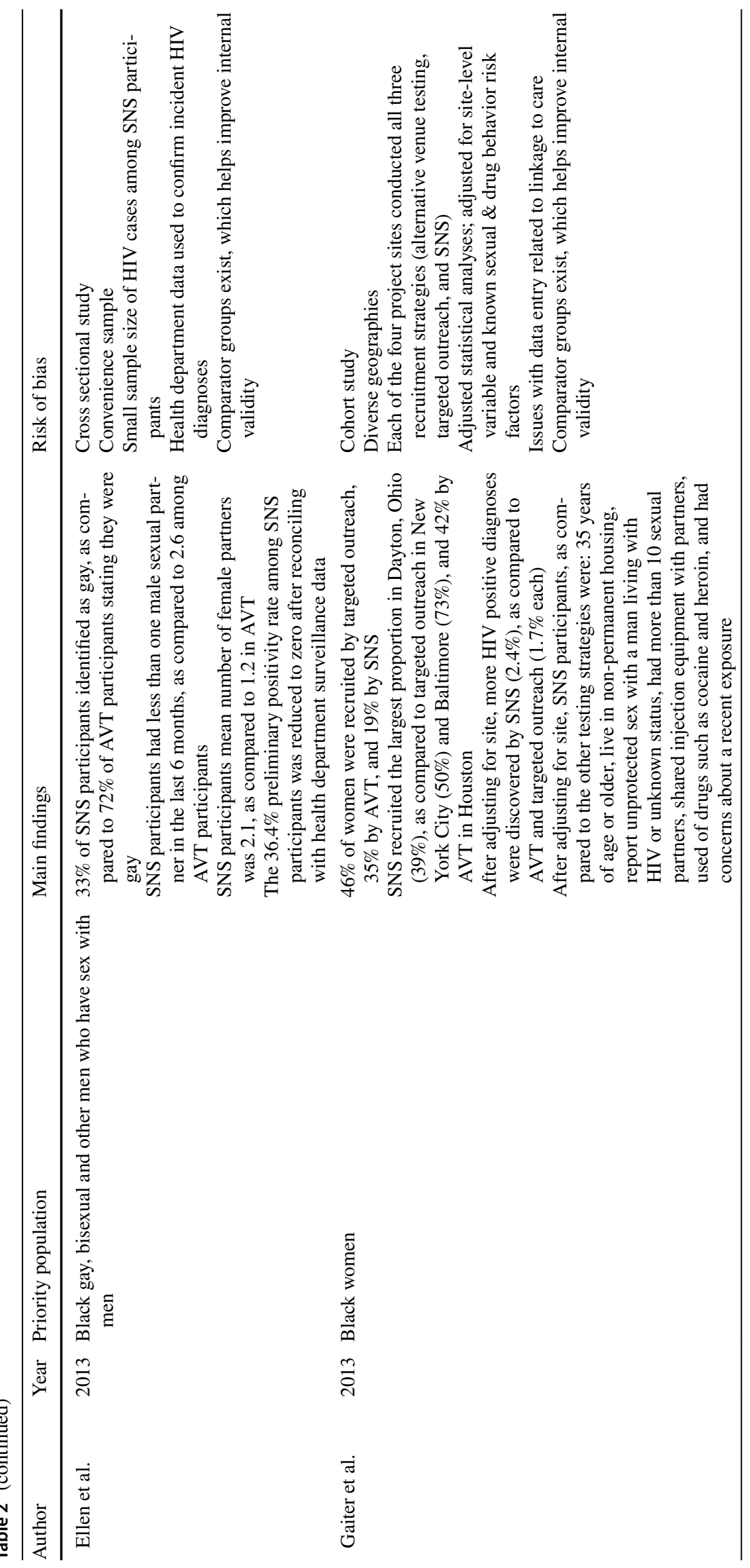




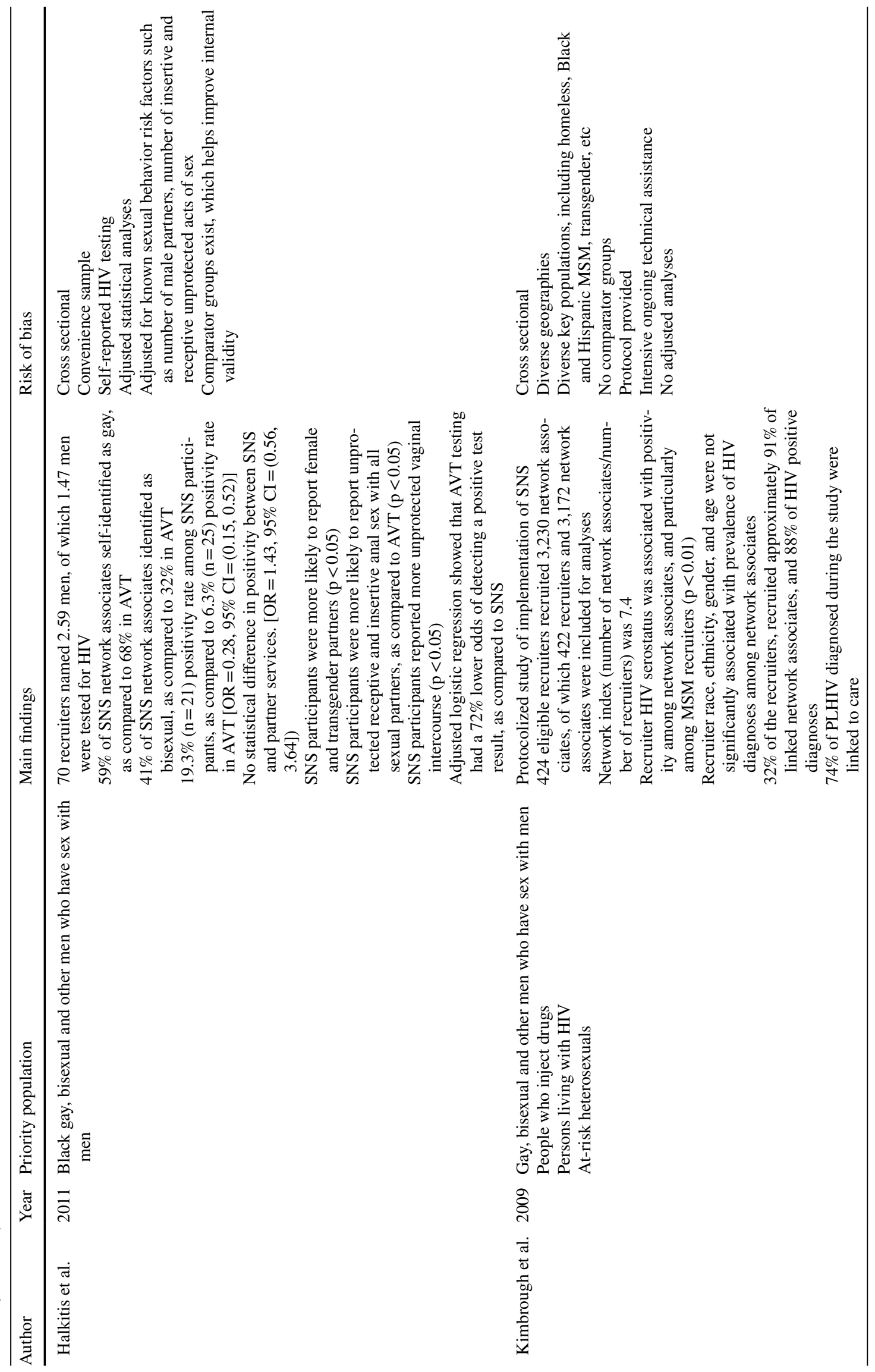




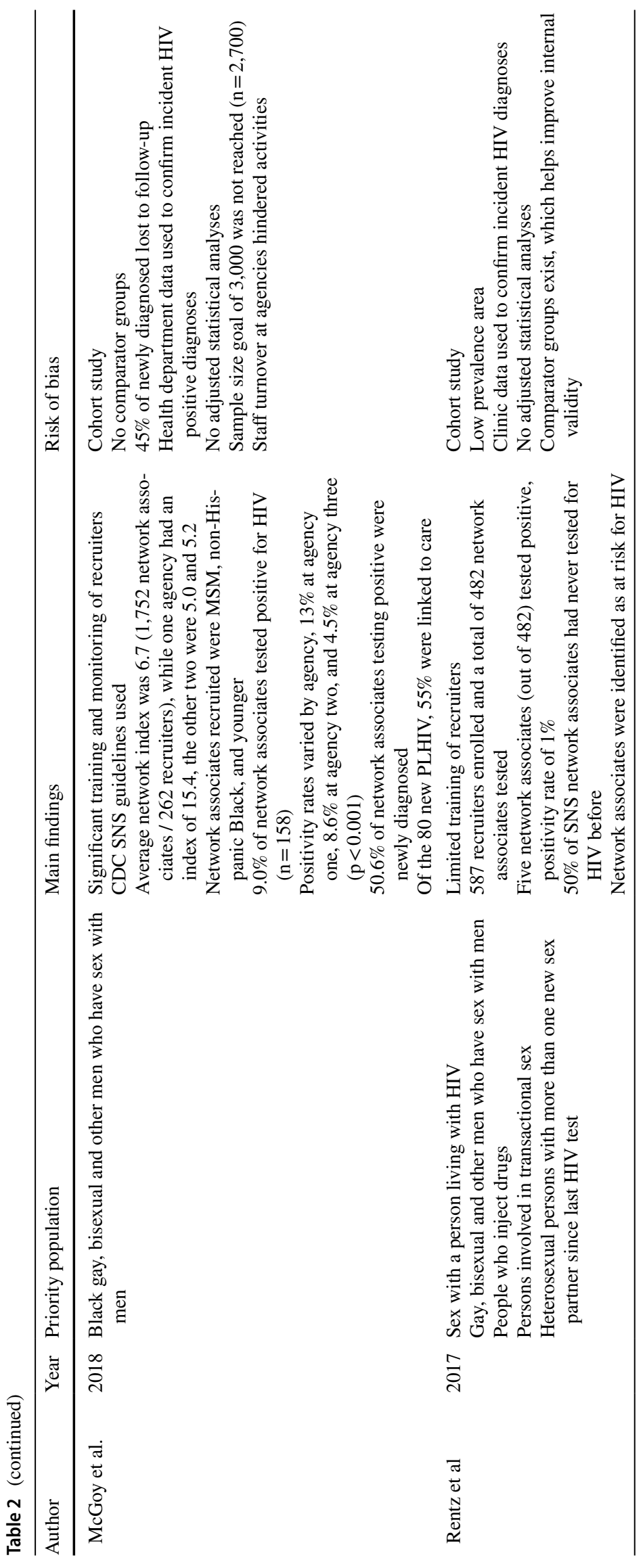




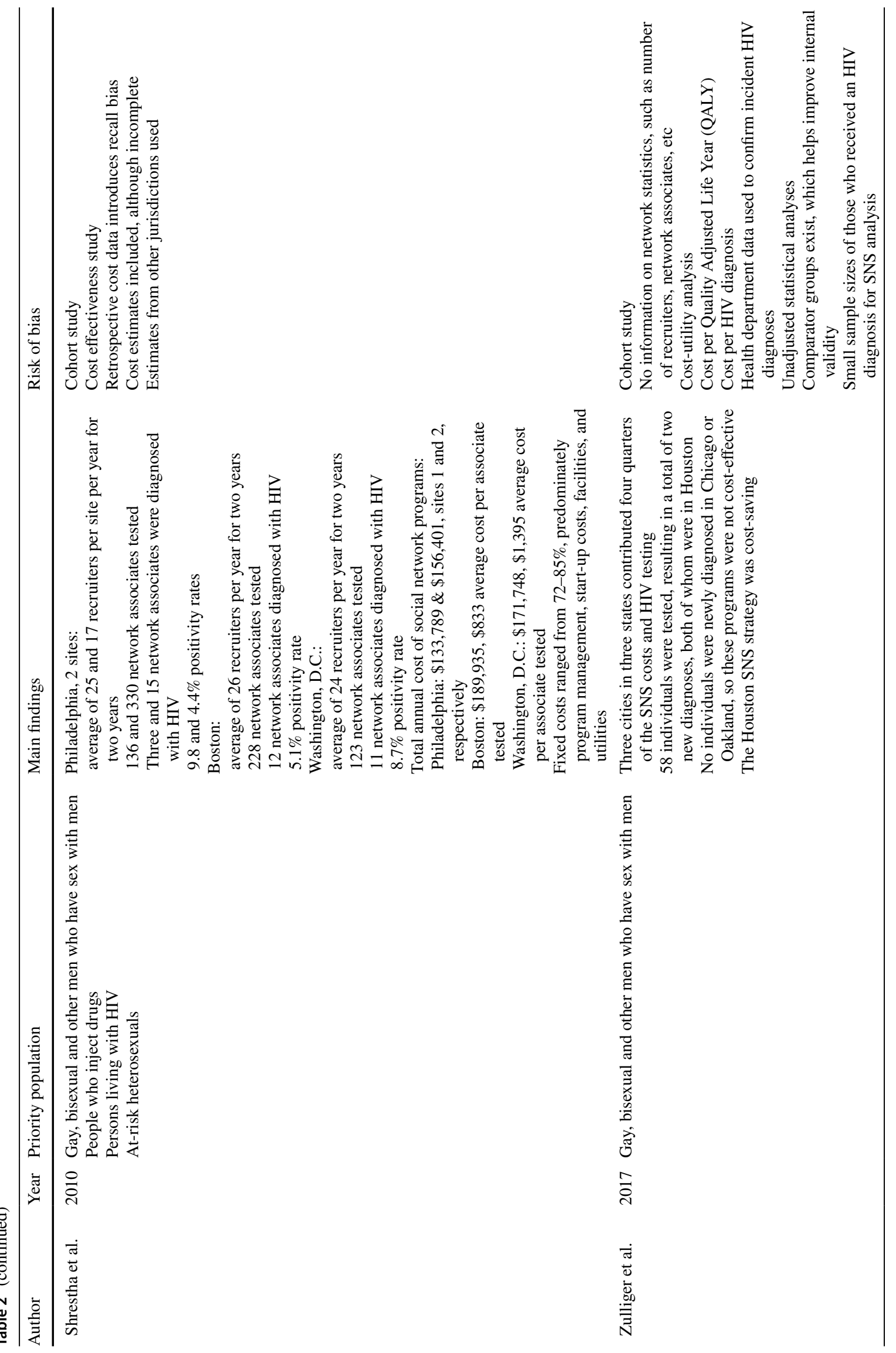




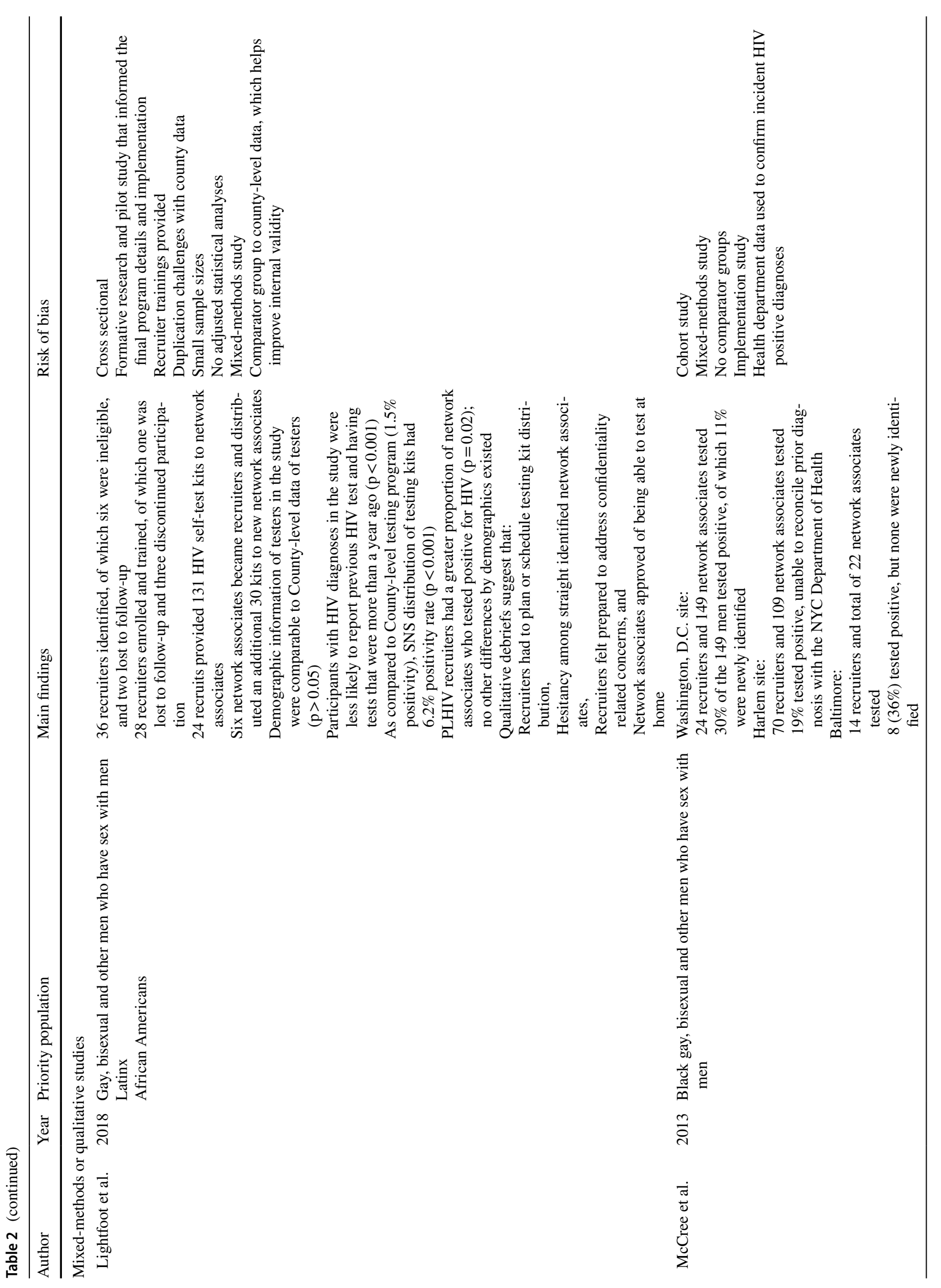




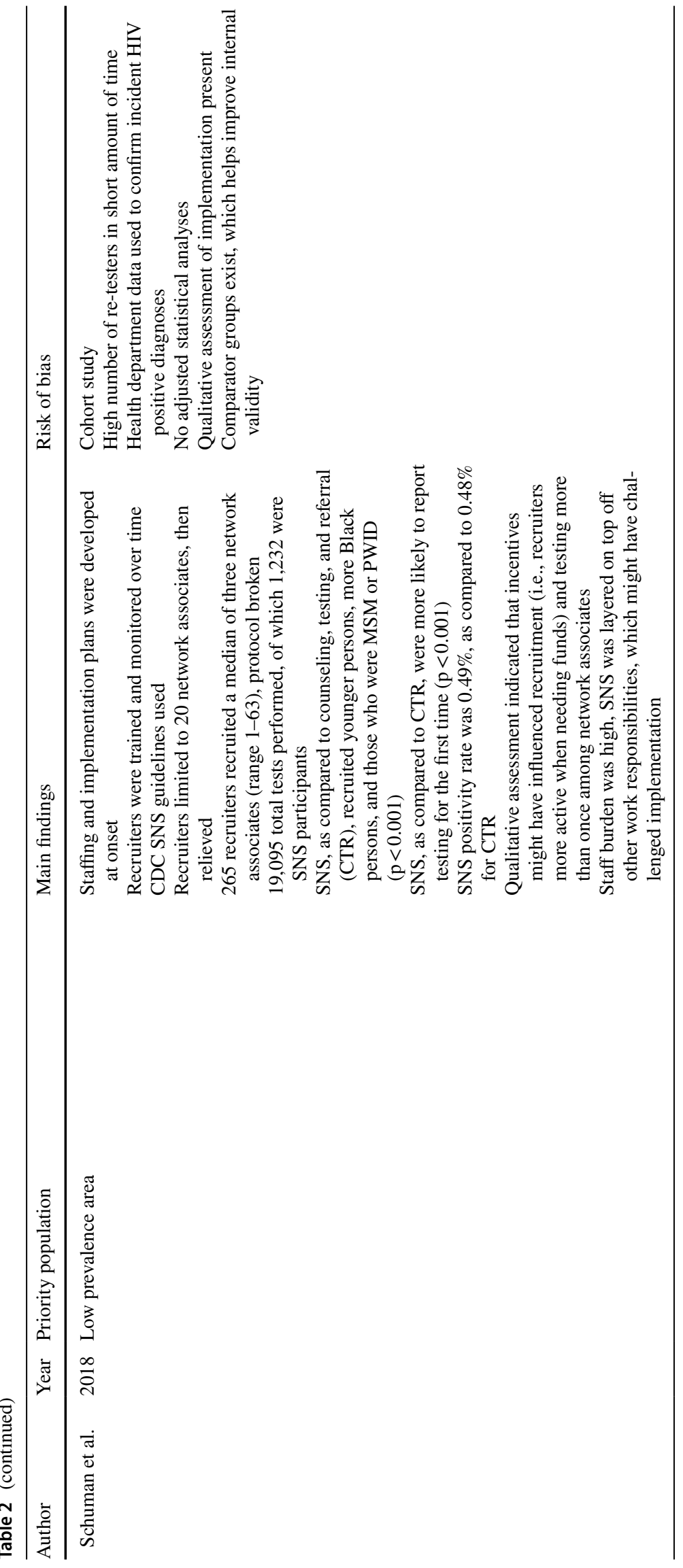


Table 3 Themes and subthemes related to implementation of SNS, 2009-2018

\begin{tabular}{|c|c|c|c|}
\hline Theme & $\begin{array}{l}\text { A priori } \\
\text { estab- } \\
\text { lished }^{*}\end{array}$ & Subthemes & Studies that support theme \\
\hline Social network and recruiter characteristics & $\times$ & $\begin{array}{l}\text { Socio-centric connected social network is important } \\
\text { to cultivate with recruiters (as exemplified with wide } \\
\text { range of network indices) } \\
\text { Homophily-like with like-can support recruiting } \\
\text { key populations in terms of HIV risk, behaviors, and } \\
\text { testing history-but not necessarily demographics } \\
\text { Recruiters, who are generally peers, are endorsed as a } \\
\text { benefit of SNS }\end{array}$ & $\begin{array}{l}\text { Baytop et al. } 2014 \\
\text { Boyer et al. } 2013 \\
\text { Ellen et al. } 2013 \\
\text { Gaiter et al. } 2013 \\
\text { Halkitis et al. } 2011 \\
\text { Kimbrough et al. } 2009 \\
\text { Lightfoot et al. } 2018 \\
\text { McGoy et al. } 2018 \\
\text { Rentz et al. } 2017 \\
\text { Schuman et al. } 2018\end{array}$ \\
\hline $\begin{array}{l}\text { Strategies for and effectiveness of recruiting } \\
\text { key populations }\end{array}$ & $\times$ & $\begin{array}{l}\text { Strategies to recruit were diverse, including use of } \\
\text { social media apps, recruiting friends, family, and } \\
\text { acquaintances, and local venues } \\
\text { Partnerships with community-based organizations are } \\
\text { important to find effective recruiters and networks } \\
\text { Risk assessments with recruiters and their networks are } \\
\text { important to support finding the "right" recruiters } \\
\text { Use of peers in SNS supports encouragement of HIV } \\
\text { testing among network associates }\end{array}$ & $\begin{array}{l}\text { Baytop et al. } 2014 \\
\text { Boyer et al. } 2014 \\
\text { Ellen et al. } 2013 \\
\text { Gaiter et al. } 2013 \\
\text { Halkitis et al. } 2011 \\
\text { Lightfoot et al. } 2018 \\
\text { McGoy et al. } 2018 \\
\text { Rentz et al. } 2017 \\
\text { Schuman et al. } 2018\end{array}$ \\
\hline Use of and types of incentives & $\times$ & $\begin{array}{l}\text { Incentives are important considerations for effective } \\
\text { recruitment } \\
\text { Incentives may inadvertently create self-interest (e.g., } \\
\text { repeat testers) } \\
\text { Incentives should match the needs of recruiters and } \\
\text { network associates } \\
\text { Incentives are diverse, including cash, gift cards, and } \\
\text { transportation vouchers }\end{array}$ & $\begin{array}{l}\text { Baytop et al. } 2014 \\
\text { Boyer et al. } 2013 \\
\text { Boyer et al. } 2014 \\
\text { Ellen et al. } 2013 \\
\text { Halkitis et al. } 2011 \\
\text { Kimbrough et al. } 2009 \\
\text { Lightfoot et al. } 2018 \\
\text { McCree et al. } 2013 \\
\text { McGoy et al. } 2018 \\
\text { Rentz et al. } 2017 \\
\text { Schuman et al. } 2018 \\
\text { Shrestha et al. } 2010\end{array}$ \\
\hline Trust, confidentiality, and stigma concerns & $\times$ & $\begin{array}{l}\text { Recruiting requires trust among network members } \\
\text { Fears exist about the confidentiality of testing and the } \\
\text { potential for an HIV positive status } \\
\text { Stigma creates challenges and fears around testing }\end{array}$ & $\begin{array}{l}\text { Boyer et al. } 2013 \\
\text { Lightfoot et al. } 2018 \\
\text { McGoy et al. } 2018\end{array}$ \\
\hline Implementation plans and real-world guidance & & $\begin{array}{l}\text { Engagement with stakeholders across community and } \\
\text { institutions } \\
\text { Collaboration with community-based organizations } \\
\text { are important } \\
\text { Collaborations with health departments for confirma- } \\
\text { tion of new diagnoses } \\
\text { Staff and organizational considerations } \\
\text { Up front training that is not time consuming and } \\
\text { burdensome } \\
\text { Clear definitions of staff roles } \\
\text { Dedicated staff to support SNS is important } \\
\text { Considerations of financial implications of implemen- } \\
\text { tation including testing, staffing, start-up costs-high } \\
\text { fixed cost } \\
\text { Attention to accessibility and availability of HIV test- } \\
\text { ing and follow-up services } \\
\text { Most studies implemented SNS for } 12 \text { months or } \\
\text { less-which challenges understanding the durability } \\
\text { of the strategy }\end{array}$ & $\begin{array}{l}\text { Boyer et al. } 2013 \\
\text { McCree et al. } 2013 \\
\text { McGoy et al. } 2018 \\
\text { Rentz et al. } 2017 \\
\text { Schuman et al. } 2018 \\
\text { Shrestha et al. } 2010 \\
\text { Zulliger et al. } 2017\end{array}$ \\
\hline
\end{tabular}

*Theme established from the Centers for Disease Control Social Network Strategy framework 
risks of the social network before beginning to recruit [40]. A cohort study in an CTR designated emergency department in a low prevalence area found that many recruiters brought in family members and acquaintances, which indicates no identifiable risk [35]. Relatedly, recruiter comfort with discussing HIV and risks is important. In a cross-sectional study, recruiters that recruited more than two network associates found that recruiters who indicated that telling girlfriends about knowing HIV status and the high rates of HIV in their community was associated with successful recruitment [40]. Barriers in this study included lack of time, difficulty in speaking about HIV, concerns about network associate believing recruiter was HIV positive, and girlfriends were afraid to know their HIV status [40]. The review of studies indicates that having the "correct" recruiter is important to the success of SNS.

Another theme was that SNS implemented in collaboration with community organizations were better equipped to find effective recruiters. In total, eight studies worked with community-based organizations (CBOs) for recruitment [32-34, 36, 39, 42-44]. Anecdotally, one agency in a cohort study, indicated they used social media to recruit network associates; this agency had the largest network index (number of network associates / number of recruiters) [34]. A study by Kimbrough noted that partnership with CBOs was important for successful and effective recruitment [44]. In a cross-sectional study, the recruiters were identified by the health department, which may have recruited different seeds and networks, as compared to community organizations [42]. In another study they described a more expansive strategy for locating recruiters including through local support groups, local gay bars, word of mouth, and through CBOs [46]. Most studies found that partnerships with CBOs supported finding effective recruiters.

Lastly, the use of social peers helped to improve the effectiveness of SNS to get people to test. In a cross-sectional study, $65 \%$ of SNS participants agreed that encouragement from peers was a facilitator to testing, as compared to $42 \%$ in AVT $(p<0.0001)$ [41]. In a qualitative study, peer recruiters reported positive experiences with distributing HIV test kits, with most stating the training prepared them and that they were motivated to help their community to test [46]. Studies that did explore the importance of peers indicated how peers help to improve HIV testing in SNS.

\section{Use of Incentives}

Incentives were used in 13 out of the 14 studies; however, there was a wide range of incentives offered, their purpose, and to whom the incentives were given. The first type of incentive was for the recruiters. For recruiters, in 10 studies, the range of incentives was \$10-25 per network-associate recruited [33-35, 38-44]. In four of the studies, the network associates had to complete their HIV test for the recruiter to receive the incentive [33-35, 38]. Four studies also gave recruiters separate incentives for agreeing to recruit, which ranged from $\$ 10$ [35] in one study, $\$ 20$ in another study [38], \$35-60 in another [41], and \$100 in a study when the recruiter finished training [46]. Network associates also received an incentive when they tested, which ranged from \$5-25 [33-35, 38, 40, 43, 44, 46]. The types of incentives offered varied, for example cash, Visa and Amazon gift cards, and transportation vouchers.

There were also challenges with incentives. One study, with many repeat testers, indicated that interest in the incentives might have been the prime motivating factor for recruiters and network associates [33]. In this study, some recruiters exceeded the 20 contacts specified by their protocol (range 1-63). In two other studies, one cross-sectional and one cohort, there were concerns that the incentives inadvertently resulted in a high number of individuals already living with HIV [38, 43]. In another cohort study, after feedback from participants, the incentive amounts were increased to align with other local testing services. This increase appeared to improve participation [38]. In one cohort study, researchers did not provide incentives, yet reached a $2.1 \%$ positivity rate [32]. In total, 13 studies that offered incentives to promote successful recruitment indicated the potential utility of incentives, which was particularly useful when the incentives were aligned with participants' needs [33-44, 46]. Overall, the majority of studies used incentives. Many described their benefits, but additional examination is needed to better understand their utility and potential pitfalls.

\section{Trust, Confidentiality and Stigma Concerns}

SNS leverages the trust between recruiters and network associates to encourage testing. However, stigma and marginalization can impede the utility of SNS to reach key populations. One study that focused on testing among Latinx women found that stigma remained a barrier to testing [40]. In four studies, SNS recruited heterosexual-identifying MSM, a highly stigmatized key population [39, 41-43]. Another study used SNS to distribute HIV self-testing kits to further reduce barriers to testing and concerns with confidentiality [46]. Qualitative results from this study indicated high levels of acceptability to test at home, as compared to the clinic, because of the opportunity for additional privacy and anonymity. However, there was no comparison group or adjusted analysis for this study. The review of studies supports SNS as a strategy that can reduce barriers to HIV testing by leveraging trust within networks; however, stigma associated with HIV testing remains. 


\section{Implementation Plans and Real-World Considerations}

The papers in this review highlighted the importance of SNS program organizers to engage with relevant stakeholders prior to implementation. All but one of the SNS programs reviewed represented a collaboration between CBOs and/or health departments. Health departments were able to reference surveillance records to reconcile whether the positivity rates were incident or prevalent cases. Of the 14 papers, eight studies (six cross-sectional and two cohort) relied on selfreport to "confirm" an incident diagnosis rather than health department or clinical records, which makes the studies subject to recall bias $[32,37,39-41,43,44,46]$. Health departments are a crucial collaborating partner for SNS to cross check HIV surveillance data when assessing positivity rates.

Implementation of an SNS program requires thoughtful consideration and planning for how to balance SNS requirements with the organization's existing policies and programs. Four studies highlighted that engagement with organizational leadership and staff is key to the success of SNS programs $[33,38,42,44]$. The four studies found that staff described difficulty taking on additional SNS-associated job duties such as tracking referrals, linking recruiters to network associates, training and supporting recruiters and supplying incentives. Also, SNS training and coaching of recruiters may be time-intensive [38, 44]. In another study, at four different sites, it was reported that SNS was least familiar to staff, it required more training, and implementation was more time consuming, as compared to AVT or targeted outreach [32]. However, SNS, when implemented by CBOs, reduces the number of persons who need to be recruited to find a undiagnosed case of HIV, as compared to other testing strategies [44]. Another cross-sectional study indicated that staffing changes and other logistical challenges hampered SNS efforts [41]. The review of papers elucidated the importance of dedicating staff and resources in order to support successful and efficient implementation of SNS. Relatedly, in the review, two of the studies conducted cost analyses. One of the studies, which had a limited number of HIV diagnoses (two positive cases out of 24 tested), showed that SNS was cost-saving for one site in the study, as compared to venue-based and voluntary counseling and testing [37]. The other study included retrospective cost data and matched unavailable cost data (e.g., mobile van costs, staff wages, and time spent on counseling and testing activities) to other similar jurisdictions. In their analyses, $72-85 \%$ of the fixed costs were related to program management, start-up costs, facilities, and utilities, which they anticipated reducing as the program matures [36]. The largest variable cost was on identifying and training recruiters. There could be other potential costs, such as home-testing kits, depending on the testing strategy used, and various incentive costs.

\section{Risk of Bias}

There were biases with some of the studies that may limit interpretation of results. As described earlier, half the studies $(n=7)$ were cross-sectional, of which six relied on selfreport to determine positivity rates. Recall bias may pose a challenge with validity in the cross-sectional studies. Five of the seven cross-sectional studies included comparison group analyses [39, 41-43, 45] and four of the seven cohort studies included comparison groups [32, 33, 35, 37]. Five cohort studies reconciled their diagnoses with health department data, which improves validity of their positivity results [33-35, 37, 38]. Twelve out of the 14 studies did not have adjusted statistical analyses, which doesn't address issues of confounding (Table 2). Only two studies focused on cost, one of which had limited numbers of persons HIV testing making the sample size small. The three mixed-method studies were robust and included quantitative and qualitative assessments that explored not only the metrics and the yield of the strategy, but the processes behind SNS. Many of the studies, especially the cross-sectional ones, were of limited duration (i.e., less than 12 months); therefore, the durability of the response is difficult to assess.

\section{Discussion}

HIV status awareness is essential to advance HIV treatment and prevention. Our systematic review of the published literature to evaluate SNS's role in detecting new HIV cases confirmed, through health department surveillance and cohort studies, that positivity rates exceeded those using standard HIV counseling, referral and testing (1\% positivity). Our thematic analysis revealed that successful SNS implementation was fostered by effectively tapping into densely connected socio-centric networks, offering incentives that align with recruiter and network needs, and leveraging strong organizational leadership and buy-in from staff. In many of the studies, SNS was able to reach key populations at heightened risk for HIV, including heterosexual-identifying MSM, persons who have never tested, and persons engaged in sexual and substance use risk behaviors.

Our findings align with other research that synthesized strategies to improve HIV testing, including a review of 15 global studies that used SNS. Campbell and colleagues noted that SNS increased HIV positivity rates from 4 to $31 \%$ across the 15 studies, nine of which were in the U.S. [21]. Campbell et al.'s synthesis found that SNS was particularly helpful to organizations and communities that historically had limited success reaching key populations for HIV testing [21]. However, that study did not examine whether positivity rates were from incident or prevalent cases. This was a strength of our analysis, in which we were able to 
draw from cohort studies and studies that collaborated with health departments to confirm new HIV diagnoses. Additionally, success of SNS may hinge on a small percentage of recruiters. For example, in one study in our review, 34\% of recruiters did not recruit any network associates, and $32 \%$ of recruiters accounted for $91 \%$ of all linked network associates [44]. The wide range of network indices found in the review of studies, 0.8 to 10 , indicated that certain recruiters may be better connected to their networks, and thus more successful in recruitment. Understanding the recruiter and their role in their network is important for the success of SNS. More explicit use of social network theories during enlistment of recruiters may be beneficial [26].

Implementation of SNS must also explore its relationship to other real-world factors that may influence its ability to reach key populations for HIV testing. For example, having explicit implementation plans, dedicated staff to SNS, and understanding how SNS overlays onto services is important (e.g., HIV testing hours). Many of the reviewed studies were 12 months or shorter, which contains challenges with understanding the durability of the public health practice. While SNS helps find new cases of HIV, testing is only the first step in the U.S. "End the HIV Epidemic" plan [1]. Linkage to treatment and prevention services are critical to fully leveraging the benefit of SNS. Understanding the underlying systems of care for persons living with HIV and those who are negative is critical to the success of SNS. As uncovered by one of the reviewed studies, $60 \%$ of those who tested positive during SNS were still not engaged in care, and it took a month to link the other $40 \%$ to care [34]. The underlying systems of HIV care and prevention, including adjacent services, such as substance use, mental health, serve as the foundation for SNS's success. Research has extensively described how collaboration with diverse stakeholders and inclusion of a multiplicity of services are critical to HIV care and prevention (47).

There are limitations to this systematic review. First, a key question in the field of SNS is defining to what extent concordance in race and ethnicity, gender identity, sexual orientation, among other factors, may be the most relevant to consider when selecting recruiters. Some studies found no variation in network associate's demographics based on the recruiter's demographics, whereas others did. Secondly, the first author was the only reviewer of the systematic review. However, the findings and tables used for analysis were shared and discussed among coauthors to ensure the accuracy of the interpretation of findings and the review. Search terms and exported search data was shared with the senior author in order to confirm the interpretation of study inclusion. In addition, $55 \%$ of the studies were found in both databases after conducting the review on each database separately. Another limitation is the caution needed to interpret the positivity rates, which is particularly true for the cross-sectional studies that relied on self-report. The cohort studies that confirmed cases with health department data and included comparator groups provide the most robust evidence for the improved reach of SNS. Lastly, many of the studies relied on convenience samples, which creates selection bias and limits the generalizability of the findings outside the study populations reviewed.

\section{Conclusion}

SNS is a promising approach to increase case detection that underpins the U.S. plan to end the HIV epidemic by 2030 . SNS programs that make use of available HIV surveillance data, engage relevant stakeholders, and dedicate sufficient resources to program staff and meaningful incentives for participants are well positioned to improve HIV testing efficiency with key populations.

Author's Contributions JF and KS conceptualized the article. KS performed the systematic review and analyses. KS drafted article with help of JF. GNR, EK, JF provided critical feedback and revisions on manuscript drafts and tables.

Funding The Capacity Building Assistance program of the San Francisco Department of Public Health is funded by The US Centers for Disease Control and Prevention (CDC) under Funding Opportunity Announcement 14-1403 and is supported by Cooperative Agreement Number 5U65PS004411-02 REVISED. The views expressed herein do not necessarily reflect the official policies of the Department of Health and Human Services or the City and County of San Francisco, nor does the mention of the San Francisco Department of Public Health or other organizations imply the endorsement by the U.S. Government of the City and County of San Francisco. We also want to acknowledge Gillian Miles at the Centers for Disease Control and Prevention for their support with this manuscript and input.

Data Availability Data are available within the tables of the article.

\section{Declarations}

Conflict of interest All authors declare they have no conflicts of interest.

Consent for participate This study does not involve human participants, and informed consent was therefore not required.

\section{References}

1. HIV.gov. What is 'Ending the HIV epidemic: a plan for America'? Ending the HIV epidemic. 2019.

2. Rodger AJ, Cambiano V, Bruun T, Vernazza P, Collins S, Degen $\mathrm{O}$, et al. Risk of HIV transmission through condomless sex in serodifferent gay couples with the HIV-positive partner taking suppressive antiretroviral therapy (PARTNER): final results of a multicentre, prospective, observational study. Lancet [Internet]. 
2019 [cited 2019]: [2428 p.]. Available from: https://linkinghub. elsevier.com/retrieve/pii/S0140673619304180

3. Cohen MS, Chen YQ, McCauley M, Gamble T, Hosseinipour MC, Kumarasamy N, et al. Prevention of HIV-1 infection with early antiretroviral therapy. N Engl J Med [Internet]. 2011 [cited 2011 Aug 11]: [493-505 pp]. Available from: https://www.ncbi.nlm. nih.gov/pmc/articles/PMC3624763/pdf/nihms412728.pdf

4. Grant R, Lama J, Anderson P, McMahan V, Liu A, Vargas L, et al. Preexposure chemoprohylaxis for HIV prevention in men who have sex with men. N Engl J Med. 2010;2010:2587-99.

5. Abdool KQ, Abdool Karim SS, Frohlich JA, Grobler AC, Baxter C, Mansoor LE, et al. Effectiveness and safety of tenofovir gel, an antiretroviral microbicide, for the prevention of HIV infection in women. Science. 2010;329:1168-74.

6. Choopanya K, Martin M, Suntharasamai P, Sangkum U, Mock PA, Leethochawalit M, et al. Antiretroviral prophylaxis for HIV infection in injecting drug users in Bangkok, Thailand (the Bangkok Tenofovir Study): a randomised, double-blind, placebo-controlled phase 3 trial. Lancet [Internet]. 2013 [cited 2013]: [2083-2090 pp]. Available from: http://dx.doi.org/https://doi.org/10.1016/ S0140-6736(13)61127-7

7. Baeten JM, Donnell D, Ndase P, Mugo NR, Campbell JD, Wangisi $\mathrm{J}$, et al. Antiretroviral Prophylaxis for HIV Prevention in Heterosexual Men and Women. N Engl J Med [Internet]. 2012 [cited 2012]: 120711140017009. Available from: http://www.nejm.org/ doi/abs/https://doi.org/10.1056/NEJMoa1108524

8. Vasylyeva TI, Friedman SR, Paraskevis D, Magiorkinis G. Integrating molecular epidemiology and social network analysis to study infectious diseases: towards a socio-molecular era for public health. Infect Genet Evol [Internet]. 2016 [cited 2016]: [248-55 pp.]. Available from: http://dx.doi.org/https://doi.org/10.1016/j. meegid.2016.05.042

9. Morgan E, Skaathun B, Schneider JA. Sexual, social, and genetic network overlap: a socio-molecular approach toward public health intervention of HIV. Am J Public Health. 2018;108(11):1528-34.

10. Parsons JT, Rendina HJ, Lassiter JM, Whitfield THF, Starks TJ, Grov C. Uptake of HIV pre-exposure prophylaxis (prep) in a national cohort of gay and bisexual men in the United States. J Acquir Immune Defic Syndr. 2017;74(3):285-92.

11. Kwakwa HA, Bessias S, Sturgis D, Walton G, Wahome R, Gaye $\mathrm{O}$, et al. Engaging United States Black Communities in HIV Preexposure Prophylaxis: Analysis of a PrEP Engagement Cascade. J Natl Med Assoc [Internet]. 2018 [cited 2018]: [480-485. pp]. Available from: https://doi.org/https://doi.org/10.1016/j.jnma. 2017.12.006

12. Gardner EM, McLees MP, Steiner JF, Del Rio C, Burman WJ. The spectrum of engagement in HIV care and its relevance to test-andtreat strategies for prevention of HIV infection. Clin Infect Dis. 2011:52(6):793-800.

13. HIV.gov. U.S. Statistics, Surveillance, People with HIV. Centers for disease control and prevention. 2019.

14. Tributino A, Montgomery MC, Bertrand T, Marak T, Almonte A, Van Den Berg J, et al. Partner notification outcomes after integration of an on-site disease intervention specialist at a sexually transmitted disease clinic. PLoS ONE. 2018;13(3):1-8.

15. Hogben M, Collins D, Hoots B, O'Connor K. Partner services in sexually transmitted disease prevention programs: a review. Sex Transm Dis. 2016;43(2):S53-62.

16. Hogben M, McNally T, McPheeters M, Hutchinson AB. The effectiveness of HIV partner counseling and referral services in increasing identification of HIV-positive individuals a systematic review. Am J Prev Med. 2007;33(2):89-100.

17. Johnson CC, Kennedy C, Fonner V, Siegfried N, Figueroa C, Dalal S, et al. Examining the effects of HIV self-testing compared to standard HIV testing services: A systematic review and metaAnalysis. J Int AIDS Soc [Internet]. 2017 [cited 2017]: [1-10 pp.].
Available from: https://doi.org/https://doi.org/10.7448/IAS.20.1. 21594

18. Carnevale C, Richards P, Cohall R, Choe J, Zitaner J, Hall N, et al. At-home testing for sexually transmitted infections during the covid-19 pandemic. Sex Transm Dis. 2021;48(1):11-4.

19. Menza TW, Garai J, Ferrer J, Hecht J. Rapid Uptake of HomeBased HIV Self-testing During Social Distancing for SARS-CoV2 Infection in Oregon. AIDS Behav [Internet]. 2021 [cited 2021]: [167-170 pp.]. Available from: https://doi.org/https://doi.org/10. 1007/s10461-020-02959-2

20. DiNenno EA, Prejean J, Irwin K, Delaney KP, Bowles K, Martin $\mathrm{T}$, et al. Recommendations for HIV screening of gay, bisexual, and other men who have sex with men-United States, 2017. MMWR Morb Mortal Wkly Rep. 2017;66(31):830-2.

21. Campbell CK, Lippman SA, Moss N, Lightfoot M. Strategies to Increase HIV Testing Among MSM: A Synthesis of the Literature. AIDS Behav [Internet]. 2018 [cited 2018]: [2387-2412 pp.]. Available from: https://doi.org/https://doi.org/10.1007/ s10461-018-2083-8

22. Biernacki P, Waldorf D. Snowball sampling: problems and techniques of chain referral sampling. Sociol Methods Res. 1981;10(2):141-63.

23. Heckathorn DD. Respondent-driven sampling ii: deriving valid population estimates from chain-referral samples of hidden populations. Soc Probl [Internet]. 2002 [cited 2002]: [11-34 pp.]. Available from: https://academic.oup.com/socpro/article-lookup/ doi/https://doi.org/10.1525/sp.2002.49.1.11

24. Coombs A, McFarland W, Ick T, Fuqua V, Buchbinder SP, Fuchs JD. Long-chain peer referral to recruit black MSM and black transgender women for an HIV vaccine efficacy trial. J Acquir Immune Defic Syndr. 2014;66(4):1-6.

25. Centers for Disease Control and Prevention. Use of social networks to identify persons with undiagnosed HIV infection-seven U.S. Cities, October 2003-September. Morb Mortal Wkly Rep. 2005;54(24):601-5

26. Liu W, Sidhu A, Beacom AM, Valente TW. Social network theory. In: Rossler P, Hoffner CA, van Zoonen L, editors. The international encylopedia of media effects. Hoboken, New Jersey: John Wiley \& Sons Inc; 2017.

27. Freeman LC. Centrality in social networks conceptual clarification. Soc Netw. 1978;1(3):215-39.

28. Marsden PV. Egocentric and sociocentric measures of network centrality. Soc Netw. 2002;24(4):407-22.

29. Ajzen I. The theory of planned behavior. Organ Behav Hum Decis Process. 1991;50:179-211.

30. Moher D, Liberati A, Tetzlaff J, Altman DG, Altman D, Antes $\mathrm{G}$, et al. Preferred reporting items for systematic reviews and meta-analyses: The PRISMA statement. PLoS Med. 2009;6(7):e1000097.

31. Vaismoradi M, Turunen H, Bondas T. Content analysis and thematic analysis: Implications for conducting a qualitative descriptive study. Nurs Heal Sci. 2013;15(3):398-405.

32. Gaiter JL, Johnson WD, Taylor E, Thadiparthi S, Duncan-Alexander T, Lemon C, et al. Sisters empowered, sisters aware: three strategies to recruit African American women for HIV testing. AIDS Educ Prev. 2013;25(3):190-202.

33. Schumann C, Kahn D, Broaddus M, Dougherty J, Elderbrook M, Vergeront $\mathrm{J}$, et al. Implementing a standardized social networks testing strategy in a low HIV prevalence jurisdiction. AIDS Behav [Internet]. 2018 [cited 2018]: [1-7 pp.]. Available from: https:// doi.org/https://doi.org/10.1007/s10461-018-2146-x

34. McGoy SL, Pettit AC, Morrison M, Alexander LR, Johnson P, Williams B, et al. Use of social network strategy among young black men who have sex with men for HIV testing, linkage to care, and reengagement in care, Tennessee, 2013-2016. Public Health Rep [Internet]. 2018 [cited 2018]: [43S-51S pp.]. Available from: 
http://journals.sagepub.com/doi/https://doi.org/10.1177/00333 54918801893

35. Rentz MF, Ruffner AH, Ancona RM, Hart KW, Kues JR, Barczak $\mathrm{CM}$, et al. Pilot Integration of HIV screening and healthcare settings with multi-component social network and partner testing for HIV detection. Curr HIV Res [Internet]. 2017 [cited 2017]: [372-381 pp.]. Available from: http://www.eurekaselect.com/ 156436/article

36. Shrestha RK, Sansom SL, Kimbrough L, Hutchinson AB, Daltry $\mathrm{D}$, Maldonado W, et al. Cost-effectiveness of using social networks to identify undiagnosed HIV infection among minority populations. J Public Heal Manag Pract. 2010;16(5):457-64.

37. Zulliger R, Maulsby C, Solomon L, Baytop C, Orr A, Nasrullah M, et al. Cost-utility of HIV testing programs among men who have sex with men in the United States. AIDS Behav. 2017;21(3):619-25.

38. McCree DH, Millett G, Baytop C, Royal S, Ellen J, Halkitis PN, et al. Lessons learned from use of social network strategy in HIV testing programs targeting African American men who have sex with men. Am J Public Health. 2013;103(10):1851-6.

39. Baytop C, Royal S, Hubbard McCree D, Simmons R, Tregerman $\mathrm{R}$, Robinson C, et al. Comparison of strategies to increase HIV testing among African-American gay, bisexual, and other men who have sex with men in Washington, DC. AIDS Care-Psychol Socio-Medical Asp AIDS/HIV [Internet]. 2014 [cited 2014]: [608-612 pp.]. Available from: http://dx.doi.org/https://doi.org/ 10.1080/09540121.2013.845280

40. Boyer CB, Hightow-Weidman L, Bethel J, Li SX, Henry-Reid L, Futterman D, et al. An assessment of the feasibility and acceptability of a friendship-based social network recruitment strategy to screen at-risk african american and hispanic/latina young women for HIV infection. JAMA Pediatr. 2013;167(3):289-96.

41. Boyer CB, Robles-Schrader GM, Li SX, Miller RL, Korelitz J, Price GN, et al. A comparison of network-based strategies for screening at- risk hispanic/latino adolescents and young adults for undiagnosed asymptomatic HIV infection. J Adolesc Heal. 2014;55(6):765-73.

42. Ellen JM, McCree DH, Muvva R, Chung SE, Miazad RM, Arrington-Sanders R, et al. Recruitment approaches to identifying newly diagnosed HIV infection among African American men who have sex with men. Int J STD AIDS. 2013;24(5):335-9.

43. Halkitis PN, Kupprat SA, McCree DH, Simons SM, Jabouin R, Hampton MC, et al. Evaluation of the relative effectiveness of three HIV testing strategies targeting African American men who have sex with men (MSM) in New York City. Ann Behav Med. 2011;42(3):361-9.

44. Kimbrough LW, Fisher HE, Jones KT, Johnson W, Thadiparthi S, Dooley S. Accessing social networks with high rates of undiagnosed HIV infection: the social networks demonstration project. Am J Public Health. 2009;99(6):1093-9.

45. Lightfoot MA, Campbell CK, Moss N, Treves-kagan S, Agnew E, Dufour MK, et al. Using a social network strategy to distribute HIV self-test kits to African American and Latino MSM. JAIDS. 2018;79(1):38-45.

46. Lightfoot MA, Campbell CK, Moss N, Treves-Kagan S, Agnew E, Kang Dufour M-S, et al. Using a social network strategy to distribute HIV self-test kits to African American and Latino MSM. JAIDS J Acquir Immune Defic Syndr [Internet]. 2018 [cited 2018]: [38-45 pp.]. Available from: http://insights.ovid.com/cross ref?an=00126334-201809010-00006

47. Jain KM, Holtgrave DR, Maulsby C, Kim JJ, Zulliger R, Massey $\mathrm{M}$, et al. Improving access to HIV care Lessons from five cities. Baltimore: Johns Hopkins University Press; 2016.

Publisher's Note Springer Nature remains neutral with regard to jurisdictional claims in published maps and institutional affiliations. 